\title{
Library's Coping Strategies for Open Access to Academic Documents
}

\author{
Xiang Hongmei \\ Library of Jilin University, Jilin, China, 130012
}

Keywords: library; academic literature; open access

Abstract: "Open access" has been rising in recent years. Its purpose is to promote the free opening of academic papers to the whole society through the mode of self-archiving and open access to journals. It has the characteristics of providing full text, network archives, free access, no authorization restrictions and high quality.

\section{The concept of open access}

The so-called Open Access means that the author and the owner of the work authorize all users to access and use the full text of the academic literature of digital chemistry indefinitely and freely through the Internet, and provide network archives. Open access is a free concept of academic information sharing. Academic achievements can be disseminated without obstacles. Any researcher can obtain and use academic achievements equally and free of charge in any place and time without the influence of economic conditions.

The main purpose of publishing scientific research results (especially in the form of papers) is not to make profits, but to disseminate their research results to the greatest extent possible. At the same time, in order to start or continue their own research, scientific researchers also hope to be able to easily access the research results of other peers. This kind of open information dissemination motivation and utilization demand makes open access a possible mode of academic services. The free and open sharing of academic papers has become a worldwide trend.

\section{Open Access Operating Model}

According to the initiative of the Budapest Open Access Promotion Association, the following two modes of operation can be adopted for the publishing of academic papers. As shown in figure 1:

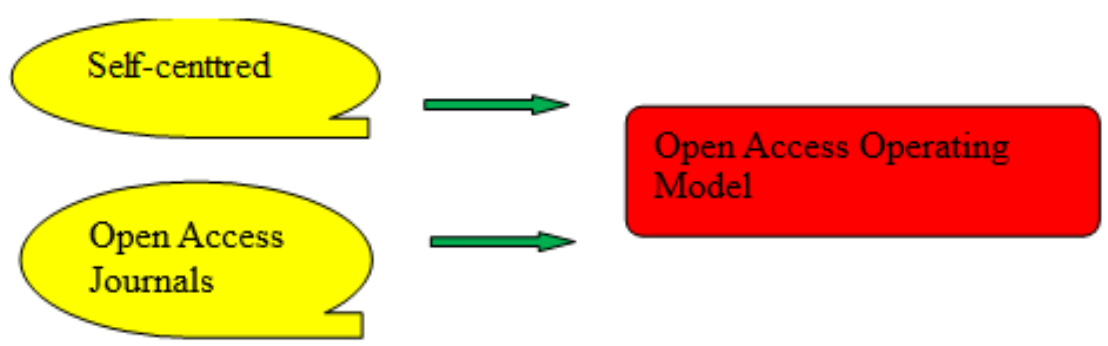

Figure 1. Open Access Operating Model 


\subsection{Self-centred}

In order to meet the standards recommended by the Open Archives Initiative (OAI), scholars can collect their open access papers by themselves, and process the scattered collections together through search engines and other network tools. Users can find and use their content without knowing what specific places there are.

The self-archiving Open Access Collection, also known as the E print Collection, can be subject-based, institution-based, or even individual-based. At present, some software systems have been developed for self-archiving construction. Among them, two are widely used: e-prints.org of Southampton University and DISPACE of MIT.

\subsection{Open Access Journals}

We should vigorously promote the development of open access journals, create new academic journals with open access business model, or change existing academic journals into open access business model. This new business model of journals will not set copyright restrictions, hinder accursedness and use, but will use copyright and other tools to ensure that their published papers are permanently open. Because prices hinder open access, these new journals will no longer charge subscription fees and access fees, but will turn to other ways to maintain revenue, such as private foundations, government subsidies, research fees of universities and research institutions, membership fees of societies or donations from supporters of open access publishing campaigns, etc., which are all possible sources of income. In addition, they can also sell additional services or even research. Investigate personnel to contribute their own funds and other ways to maintain income.

\section{The Significance and Impact of Open Access}

Scientific discovery and dissemination of scientific ideas are the basis of scientific and technological progress. If high-quality research results can be widely accessed free of charge, its role and value will be greater. Open access to literature resources is of great significance to the scientific community, the library and information community, the authors of papers, researchers and the general public.

For the scientific community, open access fully releases the right of access to full-text documents, which will greatly promote the development and progress of science. In recent years, the free and open access of genetic and molecular information science data worldwide has brought revolutionary achievements to life science and benefited all mankind. Open access to academic literature resources will bring similar huge benefits to scientific research.

$>$ Open access to periodical literature resources will help to curb the momentum of the sharp rise in subscription prices of academic journals in the field of Library and information.

The centralization and monopoly of periodical publishing industry have greatly increased the budget pressure of libraries and information institutions, and the open access to high-quality periodical resources will fundamentally solve the "periodical crisis" faced by libraries and information institutions. At present, the subscribed electronic journals of libraries have user access restrictions at the request of publishers. Most of them use the IP address of computerizes to control access rights. This makes it impossible for libraries to provide access services to electronic journals to all their legitimate readers anytime and anywhere. The open access of literature resources also fundamentally solves this problem. Open access opens up broad prospects for document resources sharing of Library and information institutions. 
Open access to the literature enlarges the influence of the research results of the authors.

Authors of academic journals do not value the contribution fee or royalty payment for publishing papers. What they need is to improve the influence of their academic research and hope that their papers will be widely disseminated and cited. Through open access, anyone can find and access their research results, which greatly increases the possibility of reading, citing and using the research results. Open access to academic literature opens the door to academic treasure house for researchers. There is no discrimination or restriction on race, region or identity. Everyone can visit and learn about the research progress and academic achievements of their predecessors or others fairly.

$>$ Open access to academic literature makes it easier for the general public to access science, understand science, and promote the popularization and influence of science.

It is precisely because of its far-reaching significance to science, education and research institutes that the Open Access Movement has aroused widespread concern. Many publications praise the epoch-making significance of the Open Access Movement, calling it a revolution in academic publishing and the future of scientific information sharing.

On August 26, 2004, 25 Nobel laureates sent an open letter to Congress in support of the Open Visit Program of the American Institute of Health (MH). On March 19, 2004, Nature magazine opened a column of online discussion, Asbestos * lighthearted: the debate continue, to discuss and track the progress of the open access movement, which was called by the academia, library and publishing circles. At the beginning of 2004, the American Institute of Science and Technology Information (ISTI) counted nearly 200 open access journals in Bioscience, and analyzed the influence of Open Access Journals in natural sciences.

All the indicators show that the academic influence of Open Access Journals exceeds that of other journals of corresponding disciplines. As shown in table 1.

Table 1. Utilization of Library Collection Resources

\begin{tabular}{|l|c|c|c|}
\hline & & Number & Percentage \\
\hline \multirow{4}{*}{$\begin{array}{l}\text { Major Ways to Get } \\
\text { Information }\end{array}$} & $\begin{array}{c}\text { Books and periodicals } \\
\text { of libraries and } \\
\text { information institutions }\end{array}$ & 45 & $22.3 \%$ \\
\cline { 2 - 4 } & $\begin{array}{c}\text { Books and periodicals } \\
\text { in bookstores }\end{array}$ & 70 & $34.9 \%$ \\
\cline { 2 - 4 } & Radio, TV, Newspaper & 88 & $44.3 \%$ \\
\cline { 2 - 4 } & network & 120 & $60.3 \%$ \\
\cline { 2 - 4 } & Other & 5 & 2.4 \\
\hline
\end{tabular}

More academic organizations and institutions responded to the Open Access Campaign with practical actions, or opened academic journals published, or established open access literature resources collection. According to DOAJ (considerateness Journal). According to statistics, there are at least 1200 peer-reviewed high-quality open access journals available on the Internet for free use by users.

\section{Coping Strategies of Libraries}

Libraries shoulder the responsibility of information and cultural dissemination. They should make full use of their own advantages to publicize the significance and role of the open access campaign, call on more scientific researchers to respond to and join the campaign, and promote the co-construction and sharing of literature resources. Open access resources, open access journals and their use methods can be introduced through user education and literature retrieval courses to maximize the role of open access resources. Librarians are encouraged to conduct relevant research, 
publish papers and participate in academic discussions in order to further promote the development of the Open Access Movement and expand its impact.

At present, Open Access Journals on the Internet are mainly foreign journals, and foreign journals have been the weakness of all library collections in China because of their high price. According to statistics, about 21000 academic journals published worldwide are peer-reviewed and Manuscript-Reviewed journals of high quality, of which 6\% (about 1200) have now become open access journals. Libraries should invest human resources in developing and utilizing these valuable resources to supplement and expand their collection by following ways: paying attention to, collecting and collating open access documents on the Internet, compiling journal cataloger and related databases in libraries, and establishing links in Library passages so that users can easily understand and use this part of the library resources on the Internet free of charge. Resources: Comparing the free and open access electronic journals on the Internet with the journals ordered by the library, integrating and deleting the existing Journal Resources in order to save the limited cost of books and periodicals.

Libraries should actively support and participate in the Open Access Campaign and implement the Open Access Document Collection. First, we can use the advantages of manpower, material resources, technology and resources to build open access electronic archives in our region and institute. For example, university libraries can set up electronic pre-pay archives servers, provide electronic pre-pay archives services for school teachers, and introduce the research results of teachers and teaching and research personnel. Secondly, it helps researchers to add their research papers to the open access archives of corresponding disciplines or institutions. Thirdly, we try to publish open access journals and support the open access movement by publishing open access journals.

\section{Conclusion}

When the American Journal of Science, published on December 19, 2003, predicted major changes in the field of global scientific research and policy in 2004, it believed that the opening of academic journals would become a scientific hot spot in 2004. In the past year, the Open Access Campaign has been accepted by more and more people, more and more people are involved in the Open Access Campaign, and its momentum of development is growing, which has been confirmed. We believe that in the next few years, with the progress of science, especially the development of Internet technology, and the deepening of the open access movement in universities at home and abroad, profound changes will take place in the way of academic exchanges. The unbalance and obstacles of the dissemination of academic resources and information will be gradually eliminated, and the open access movement will become a worldwide trend.

\section{References}

[1] Li Wu, Liu Ziheng. A brand-new academic publishing mode: an analysis of open access publishing mode. Journal of Chinese Library, 2004 (6)

[2] Edited by Zhejiang Library Society. Library and Information Services in the New Century. Hong Kong: Baitong Publishing House, 2004

[3] Zhou Qingshan. Document Communication. Beijing: Bibliographic Literature Publishing House, 1997.4

[4] Li Li, Zhang Chengyu. Open Document Pioneer and Its Impact on Digital Communication of Academic Journals. Editorial Journal, 2004 (1)

[5] About Sindap. http://sindap.istic.ac.cn/sindap/about.htm, 2005.1 